University of Nebraska - Lincoln

DigitalCommons@University of Nebraska - Lincoln

Faculty Publications, Department of Psychology

Psychology, Department of

2016

\title{
Examining the Reasons for Student Responses to Threatening Behaviors on a College Campus
}

\author{
Heath J. Hodges \\ University of Nebraska-Lincoln \\ Elizabeth C. Low \\ University of Nebraska-Lincoln, elow2@unl.edu \\ M. Rosa Viñas-Racionero \\ University of Nebraska-Lincoln, r.v.racionero@gmail.com \\ Brandon A. Hollister \\ University of Nebraska-Lincoln \\ Mario Scalora \\ University of Nebraska-Lincoln, mscalora1@unl.edu
}

Follow this and additional works at: https://digitalcommons.unl.edu/psychfacpub

Part of the Domestic and Intimate Partner Violence Commons, Psychology Commons, Social Control, Law, Crime, and Deviance Commons, and the Terrorism Studies Commons

Hodges, Heath J.; Low, Elizabeth C.; Viñas-Racionero, M. Rosa; Hollister, Brandon A.; and Scalora, Mario, "Examining the Reasons for Student Responses to Threatening Behaviors on a College Campus" (2016). Faculty Publications, Department of Psychology. 825.

https://digitalcommons.unl.edu/psychfacpub/825

This Article is brought to you for free and open access by the Psychology, Department of at DigitalCommons@University of Nebraska - Lincoln. It has been accepted for inclusion in Faculty Publications, Department of Psychology by an authorized administrator of DigitalCommons@University of Nebraska - Lincoln. 
Published in Journal of Threat Assessment and Management 3:3-4 (2016), pp 129-142. doi 10.1037/tamooooo63

Copyright (C) 2016 American Psychological Association. Used by permission. "This article may not exactly replicate the final version published in the APA journal. It is not the copy of record."

Submitted December 21, 2015; revised May 4, 2016; accepted May 23, 2016; published October 13, 2016.

\title{
Examining the Reasons for Student Responses to Threatening Behaviors on a College Campus
}

\author{
Heath J. Hodges, Elizabeth C. Low, \\ M. Rosa Viñas-Racionero, Brandon A. Hollister, \\ and Mario J. Scalora \\ University of Nebraska-Lincoln
}

Corresponding author - Mario J. Scalora, Department of Psychology, University of Nebraska-Lincoln, 238 Burnett Hall, Lincoln, NE 68588-0308. email mscalora1@unl.edu

\begin{abstract}
Underreporting criminal activity to authorities can pose significant challenges, particularly within college campuses. Crime prevention teams have recognized the importance of reporting potentially concerning behaviors that may precede violent acts. However, reasons for reporting preincident behaviors have been understudied among college samples and failed to account for informal responses, such as talking to third parties or changing personal security features. The present study surveyed 1,075 students from a midwestern state university and evaluated their awareness of threatening or concerning behaviors on campus, response behaviors, and reasons for either acting on or failing to report preincident behaviors. Findings reflected reporting rates $(12.3 \%)$ consistent with the scientific literature but revealed informal responding as the most common reaction to preincident behaviors (44.6\%). Reasons for not taking action included a desire to be uninvolved and perceiving the situation as unlikely to be immediately dangerous. By contrast, those who reported preincident behaviors appraised the situation as immediately dangerous and likely to result in harm. Their most influential reason for notifying police or university authorities involved an awareness
\end{abstract}


of campus resources. Informal responders perceived situations as less dangerous and demonstrated less awareness of campus resources. Compared with those who took no action, informal responders were more influenced by their relationship to the potentially dangerous individual and beliefs that police involvement was either unnecessary or might escalate the situation. These findings identify informal responding as the most prevalent reaction to threatening or concerning preincident behaviors and suggest that different interventions may be appropriate for various bystanders.

Keywords: campus community, threat assessment, reporting, college students

Underreporting of criminal activity to authorities can pose significant challenges, especially within college campuses. A review of victimization survey data from 1992 to 2010 revealed that police are notified of approximately $40 \%$ of community criminal activity (Bosick, Rennison, Gover, \& Dodge, 2012). Findings from the most recent National Crime Victimization Survey (NCVS) indicate that $46 \%$ of violent crimes (i.e., rape or sexual assault, robbery, aggravated assault, and simple assault) and 61\% of serious violent crimes (i.e., excluding simple assault) are reported to police (Truman \& Langton, 2014). There is evidence to suggest that reporting rates may be even lower for crimes committed on college campuses. Through use of an anonymous Internet survey, Buhi, Clayton, and Surrency (2009) found that almost half (47.4\%) of college women who had experienced stalking did not seek outside help and that very few reported the behaviors to college personnel $(12.2 \%)$ or police $(7.3 \%)$. These rates drop dramatically with more serious crimes, such as physical (2.2\%; Thompson, Sitterle, Clay, \& Kingree, 2007) and sexual assaults (2.1\%, Fisher, Daigle, Cullen, \& Turner, 2003; 1.4\%, Thompson, Sitterle, Clay, \& Kingree, 2007). Given the low rates for postincident reporting, the current study reviewed potential crime prevention through reporting of behaviors preceding the incident and response behaviors, or actions taken in response to the concerning behavior. These response behaviors included the decision to report the action as well as informal responses that did not involve reporting, such as talking to third parties or changing personal security features. 


\section{Pre-Incident Reporting}

Targeted attacks tend to be prefaced by planned behavioral commonalities (Calhoun \& Weston, 2003). Some of these behaviors may be indicative of foreseeable violence and have been termed "pre-incident behaviors" (Drysdale, Modzeleski, \& Simons, 2010, p. 18). Preincident behaviors are not redundant with "risk factors" for violence, which are variables that precede and increase the likelihood for general risk of violence (Scalora et al., 2003). Rather, preincident behaviors are behaviors specifically "directed toward the targets prior to the [violent] incidents" (Drysdale et al., 2010, p. 21). These can include verbal/written threats, stalking or harassing behavior, and physically aggressive acts. Of course, preincident behaviors themselves may be considered violent, harmful, and illegal in many jurisdictions across the world. It therefore remains critical to intervene when preincident behaviors occur because of the harm they can cause as well as their potential to escalate to more severe forms of violence. The first step of violence prevention, including threat assessment, is to identify threatening individuals through becoming aware of preincident behaviors (Drysdale et al., 2010; Fein \& Vossekuil, 1999).

The threat assessment literature supports the effectiveness of reporting preincident behaviors in the disruption of future violent incidents. For example, Cornell et al. (2004) conducted a field test within 35 different schools over a period of one year and, using a threat management strategy that matched intervention to seriousness of the threat, were able to prevent all of nearly 200 potential acts of violence. Daniels and colleagues found that $57 \%$ of averted K-12 school shootings were attributable to students alerting authority figures (Daniels et al., 2007). Similarly, college campuses face numerous targeted violence opportunities that may impact various stakeholders, including students, staff, and visiting members of the public. College campus environments involve a diversity of potentially threatening situations, including concerns from loosely affiliated or nonaffiliated individuals, and typically include large and publicly accessible grounds (Drysdale et al., 2010). College students are involved in a lifestyle with greater independence and are subject to less supervision than other protected settings (e.g., work environments; Scalora, Simons, \& VanSlyke, 2010). Thus, violence prevention activities can be greatly assisted through the reporting of preincident observances from collegiate stakeholders. 
Unfortunately, preincident behaviors are not consistently reported to protection authorities (Calhoun \& Weston, 2009; Meloy, 2011; Pollack, Modzeleski, \& Rooney, 2008; Sulkowski, 2011).

Incidents of concerning or threatening behavior may also involve bystanders who observe or are indirectly informed about the situation. Bystanders, as defined for this paper, include nonauthority figures who become aware of or witness activity but are not directly involved in perpetration or victimization. A review of the literature reveals that bystanders observe threatening behaviors prior to many criminal incidents (Bosick et al., 2012; Buhi et al., 2009; Paull, Omari, \& Standen, 2012). Drysdale and colleagues (2010) found that bystanders observed preincident behaviors for 31\% of completed campus attacks (p. 23). In a report on high-profile school shootings, at least one person had knowledge of the attacker's plan in $81 \%$ of the incidents, and more than one person had such knowledge in 59\% of the incidents (Vossekuil, Fein, Reddy, Borum, \& Modzeleski, 2002). Thus, perpetrators and victims, referred to as targets from this point forward, appear to notify bystanders of preincident behaviors with much greater frequency than law enforcement is being notified. It therefore follows that threat assessment efforts should target bystander as well as target reporting.

The facilitation of reporting behaviors serves multiple functions. Scholars have suggested that unreported crime may hinder the deterrence and incapacitation goals of the criminal justice system (Skogan, 1994). Targets otherwise restricted from compensation or victim-assistance services may gain access to assistance (Frazier \& Burnett, 1994). Proper forewarning may result in successful preventive responses by campus threat assessment teams (Scalora et al., 2010). In order to bolster preincident reporting, it is necessary to understand the reasons for different response behaviors and their implications for violence prevention.

\section{Reasons for Reporting}

The decision to report threatening preincident behaviors is not a simple one. Reasons for reporting have been largely studied within general crime prevention domains (e.g., bullying, sexual assault). This phenomenon has been less extensively studied in the context of 
campus threat assessment. Early research on campus reporting was limited to notifications to security professionals and failed to account for communication of threats to school authorities. Yet, recent reviews on this issue suggest that concerning preincident behaviors for campus threats may be observed by multiple parties (Hollister \& Scalora, 2015). Research thus far suggests that responses are influenced by characteristics of the incident, reporter, and offender. Studies have consistently found that females across various age groups are more likely than men to report threatening or criminal activity (Brank et al., 2007; Slocum, Taylor, Brick, \& Esbensen, 2010). In college populations, men tend to minimize the seriousness of the threatening behaviors and attribute less culpability to the perpetrator (Yamawaki, Ochoa- Shipp, Pulsipher, Harlos, \& Swindler, 2012). Willingness to report among college students has been linked to attitudes related to trust in campus services and perceived connection to the campus (Sulkowski, 2011), as well as knowledge and awareness of campus resources (Foubert \& Perry, 2007). Certain features of the target behavior tend to prompt reporting, such as direct threats, more serious threats, or security breaches involving a weapon (Tarling \& Morris, 2010). Further, college students are more likely to report incidents that involve property damage, physical following, and assault (Hollister, Hoff, Hodges, Scalora, \& Marquez, 2015).

By contrast, there are characteristics associated with unwillingness to report threatening behaviors. The literature identifies certain groups as especially resistant to reporting, including those with a history of antisocial behavior themselves (Sulkowski, 2011), lower income individuals (Tarling \& Morris, 2010), and certain ethnic groups (Thompson et al., 2007). Campus-related attitudes linked to nonreporting include a lack of trust in police, viewing the situation as insignificant, and low campus connectedness (Buhi et al., 2009). Offcampus incidents, more severe assaults, target unemployment, and target alcohol consumption have all been linked to reduced likelihood to report (MacDonald, 2001; Thompson et al., 2007). Contrary to what might be believed, context of the incident (e.g., involving an intimate relationship, presence of mental health issues) and type of concerning behavior (e.g., sexual assault/ touching, threats) may not substantially influence reporting decisions (Hollister et al., 2015). 


\section{Response Behaviors}

Response behaviors are defined as the reaction( $\mathrm{s}$ ) taken by individuals who have either observed or been made aware of a concerning behavior. Two studies have addressed response behaviors. Hollister, Scalora, Hoff, and Marquez (2014) explored a collegiate sample that contained 450 participants. The authors analyzed the proportion of students who had observed concerning behaviors and compared their willingness to report among 12 vignettes. Demographics, self-reported delinquency, and various attitudinal variables (i.e., campus connectedness, peer loyalty, perceptions of campus safety, and perceptions of campus police) were considered. Results indicated $35 \%$ of the sample had observed concerning behaviors on campus and that $43 \%$ of the sample was willing to report preincident behaviors across vignette scenarios. Observers of concerning behaviors indicated more connection to campus, less campus safety, and less favorable feelings toward campus police. When examining willingness to report for various vignettes, reporters were more likely to be female, have higher class standing, endorse lower campus safety, and stated more favorable feelings about campus police.

A subsequent study explored a much larger dataset $(N=1,735)$ and considered additional features that might influence reporting decisions (Hollister et al., 2015). These variables included ethnicity, estimations of peer norms, beliefs in a fair world, and multiple incident-related factors (e.g., relationship to perpetrator, personal victimization). Results supported the previously identified reasons for willingness to report as stated in Hollister et al. (2014). Furthermore, willingness to report was significantly higher among participants who had reportedly experienced personal victimization, witnessed the perpetrator engage in physical or sexual assault, and observed vandalism or property theft from the perpetrator. Thus, the more categories of concerning behavior that were observed, the more likely the individual was to report the potentially dangerous person to authorities.

The follow-up to these studies, which forms the basis of this manuscript, represents an increment above previous publications with this dataset in two ways. First, investigators wished to expand the reach of past findings concerning vignette scenarios by evaluating reasons for reporting in actual instances of concerning behaviors of which the 
participant was aware. In this regard, this study addresses the external validity issues regarding the behaviors of interest posed by the preceding manuscripts. Second, authors sought to examine response behaviors with greater scrutiny than previously addressed by analyzing informal and alternative responses to concerning behaviors. In this effort, the authors considered the outcome measure beyond the traditional report/no-report dichotomy to include an array of involvement behaviors that did not rise to the level of notifying university officials or law enforcement.

The decision to explore informal responding was influenced by prior research efforts that have used informal or unofficial approaches to measuring response behaviors rather than utilizing the dichotomous report-no report approach that is often found in the literature. For example, evidence suggests that targets inform friends and relatives at much higher rates than they inform law enforcement (Buhi et al., 2009; Tarling \& Morris, 2010) and that bystanders may utilize "neutralization techniques" that fall short of actual reporting to authorities (Pershing, 2003, p. 149). Unfortunately, most of the literature has failed to account for informal actions. This class of "informal responders" presents a lucrative population for threat assessment attention since these individuals are, by definition, aware of the situation and making some initiative to intervene. Understanding their reasons for taking some action, but failing to involve authorities, may provide insight for increasing reporting behaviors to authorities. Further, this cohort represents an ambivalent target group for threat assessment professionals and may therefore be especially responsive to reporting enhancement strategies.

The present study sought to investigate the reasons for individuals, whether targets or bystanders, who decide to take informal action in response to concerning behaviors but fail to go so far as to report the situation to authorities. In this sense, we examined two critical questions: (1) why did the individual take any action instead of no action? and (2) why did the individual fail to report the behavior while still taking some action? This study extends the literature on reporting in a number of ways. First, as mentioned earlier, the issue of informal response behaviors has been relatively under-researched. Second, most of the studies on reporting limit the scope to one type of threatening behavior (e.g., stalking, sexual assault). This 
study investigated a range of threatening behaviors, which allows for comparisons across variable behaviors of concern. Third, many studies on reporting behaviors have utilized vignette designs (e.g., Hollister et al., 2015; Sulkowski, 2011; Yamawaki et al., 2012). While this may be a useful analogue, the reporting rates for actual targets of crimes are grossly lower than the rates of reporting in response to vignettes (e.g., 69\% willing to report hypothetical threats of violence vs. 2.2\% report rate for actual targets of physical victimization; Sulkowski, 2011; Thompson et al., 2007).

This study examined the following hypotheses. First, most participants were expected to report taking some type of informal action relative to other response behaviors. Second, in line with past research, proportionately more females were anticipated to report concerning behaviors than males. Third, we hypothesized that informal responders would perceive situations as less dangerous than reporters, who would emphasize the severity of the threatening behavior when deciding to notify authorities compared with those who failed to report the individual. Specifically, multiple contacts, the presence of a weapon, and direct threats were expected to be associated with the decision to report the potentially dangerous individual to authorities. Last, nonresponders were expected to endorse greater trust in police, connectedness to the campus, awareness of campus resources, and to perceive the concerning situation as significant. Similarly, it was hypothesized that informal responders would indicate not reporting due to increased perceptions of dangerousness. Specifically, they were expected to see the concerning situation as more imminently dangerous and more likely to result in a dangerous outcome.

\section{Method}

\section{Participants}

A total of 1,075 students responded to an online survey that was advertised to undergraduates in an introductory psychology class as an option for class credit. Of these, 415 participants (30.4\%) reported being aware of a person who had made someone else intimidated or fearful for his or her safety while on campus. Responses from these 415 participants were analyzed for the purposes of this study. Students 
in the sample were predominantly female $(n=270,65.4 \%)$ and were between the ages of 18 to 37 years $(M=20.1, S D=2.0)$. The majority of participants identified as White ( $n=357,86.4 \%)$, with few individuals identifying as Hispanic ( $n=20,4.8 \%)$, Black $(n=17,4.1 \%)$, Asian/Pacific Islander $(n=10,2.4 \%)$, or Other $(n=2,2.2 \%)$. Approximately a third of the sample was freshman ( $n=136,32.9 \%)$, followed by a relatively equal dispersion of participants in their second ( $n=94$, $22.8 \%$ ), third ( $n=98,23.7 \%)$, and fourth years ( $n=68,16.5 \%)$ of college. The reported grade point averages of participants indicated students of good academic standing $(M=3.31, S D=0.52)$.

\section{Procedure}

The data analyzed here were collected as part of previously conducted studies (see Hollister et al., 2015; Hollister et al., 2014). The methodology and primary results from responses to vignette scenarios are detailed in these publications. Undergraduate students from a large Midwestern university were invited to complete an online survey in exchange for course credit. If interested, students were directed to an anonymous online recruitment tool (i.e., Experimetrix, Sona), which subsequently directed them to the online consent and survey materials (i.e., Qualtrics). These surveys were contained within a passwordprotected account accessible only to investigators. Qualtrics encrypts all transmitted data and protects data through firewall systems. Survey completion took approximately $20 \mathrm{~min}$, after which, students were provided with a debriefing document that included the researchers' contact information.

In contrast to the two past publications utilizing this dataset, this manuscript examined previously unexplored data in three important respects. First, participants' responses to actual incidents of concerning behaviors (not vignettes) were the focus of this study. Second, analyses considered the additional outcome of informal responses to incidents rather than the traditional report/no-report dichotomy. Third, the independent variables utilized for the predictive model consisted of participant indicated reasons for responding in addition to indirect proxies for reporting decisions. To avoid redundancy with previous studies with this dataset, only those predictors shown to be significantly related to reporting decisions were included in the model in order to determine whether their predictive value was influenced 
by self-reported reasons for response behaviors. These variables included: gender, multiple threatening contacts, direct verbal threats, campus connectedness, and whether the potentially dangerous person had acquired a weapon.

\section{Independent Variables}

Target and bystander status. All participants included in analyses indicated being aware of an individual who had intimidated another person on campus or caused that person to be fearful of his or her safety. Participants were asked to provide details on the most recent incident through multiple-choice questions. A minority of participants identified themselves as the target of the threatening behaviors ( $n=$ 37, 9.0\%), while most individuals identified themselves as third parties who were aware of the incident (i.e., bystanders; $n=376,91.0 \%$ ).

Awareness of concerning behaviors. Participants were asked to select any threatening behaviors of which they were aware from a list of options provided on the survey. Participants were allowed to select multiple threatening behaviors. Most of the sample ( $n=227,55.0 \%)$ reported being aware of more than one threatening behavior, with an average of two threatening behaviors $(M=2.1, S D=1.4)$ known by each participant. The most common types of concerning behaviors were verbal in nature, including threatening statements $(n=162$, $39.2 \%)$, threatening gestures ( $n=130,31.5 \%)$, and unwanted verbal contacts through e-mail or phone $(n=128,31.0 \%)$. Less common were incidents of physical assault ( $n=45,10.9 \%)$ and sexual assault or touching ( $n=52,12.6 \%)$.

Campus connectedness. Participants answered the 14 self-report questions of the Campus Connectedness Scale (CCS; Summers, Gorin, Beretvas, \& Svinicki, 2005), which measures participants' attachment with the collegiate community. Greater CCS scores correspond with more campus connectedness. The CCS has excellent internal consistency in college student samples (Hollister et al., 2014; Sulkowski, 2011).

Reasons for response behaviors. For participants who reported taking some form of action (i.e., informal responders and reporters), they were asked to select from a list of eight circumstances that were 
important for their decision. These options included the participant's perceptions of dangerousness (i.e., immediacy, likelihood, "gut" feeling), relationship with the potentially dangerous individual, features of the conduct (i.e., specific/serious threats, presence of harm, changes in personality or behavior of the potentially dangerous individual), and awareness of campus resources. For participants who failed to report the threatening behaviors (i.e., informal responders and those who took no action), they were asked to select among 14 reasons for not reporting the individual to campus authorities or law enforcement. These entailed the same eight reasons for taking action as well as six additional options that might hinder responding, including preferred level of involvement (i.e., personal matter, not wishing to get involved, concern about putting self in danger), police efficacy (i.e., police could or would not assist), and personal efficacy (i.e., reporting would make the situation worse).

\section{Dependent Variables}

Response behaviors. Participants were allowed to select among 10 different multiple-choice responses to the concerning behavior. These were grouped into one of three categories based upon level of involvement: No Action, informal response, or reporting. The No action group $(n=178)$ encompassed participants who reported doing nothing in response to the threatening behavior. Individuals in the Reporting group ( $n=51$ ) involved persons who reported informing university authorities or police about the behavior. Last, the Informal Response group ( $n$ $=184$ ) consisted of any response short of reporting, including changing personal security, talking with the potentially dangerous individual, requesting a third party talk to the potentially dangerous individual, talking to a friend, collecting or saving evidence, or speaking to a trusted individual.

\section{Results}

\section{Response Behaviors}

As hypothesized, the majority of participants were informal responders who reacted to the concerning behavior(s) by taking action that 
did not involve notifying authorities ( $n=184,44.6 \%)$. Of the informal responders, the majority talked to the individual who displayed concerning behavior ( $n=83,20.1 \%$ ), trusted this individual to inhibit the aggressive behavior ( $n=67,16.2 \%$ ), or talked to a friend about what they observed ( $n=82,19.9 \%)$. A smaller proportion of the sample were nonresponders, who took no action in response to concerning behaviors ( $n=178,43.1 \%$ ). Only a small number of participants were reporters, who reported observed concerning behaviors to the authorities ( $n=51,12.3 \%$ ). Reporters were equally likely to notify university administrators $(n=29,7.0 \%)$ as they were to contact police ( $n=36,8.7 \%$ ) about concerning behaviors. See Table 1 for the frequencies of specific response behaviors and groups. These response types were not equally distributed, $\chi^{2}(2)=81.971, p<.001$. Rates of informal response and taking no action did not differ from each other, $\chi^{2}(1)=.099, p<.752$, but both were significantly greater than the rate of reporting to the authorities, $\chi^{2}(1)=75.272, p<.001$, and $\chi^{2}(1)=70.432, p<.001$, respectively. Response behaviors did not differ by age, ethnicity, or educational status.

\section{Target and Bystander Comparisons}

Response behaviors did not differ by target or bystander status. Reasons for responses only differed between targets and bystanders for three reasons: targets were more likely than bystanders to report due

Table 1. Frequencies for Different Responses to Concerning Behaviors

\begin{tabular}{lrc} 
Response behavior & $n$ & $\%$ \\
\hline No action & 178 & 43.1 \\
Informal response & 184 & 44.6 \\
Talked with individual & 83 & 20.1 \\
Talk to a friend & 82 & 19.9 \\
Trusted individual & 67 & 16.2 \\
Had a third party talking with individual & 33 & 7.9 \\
Change personal security & 23 & 5.6 \\
Collected or saved evidence & 16 & 3.9 \\
Other & 10 & 2.4 \\
Report & 51 & 12.3 \\
Notified police & 36 & 8.7 \\
Notified university administrator & 29 & 7
\end{tabular}


to their relationship with the potentially dangerous individual $(42.1 \%$ vs. $16.9 \%), \chi^{2}(1)=7.172, p<.007$, and more likely to refrain from reporting because the individual did not make any threats of violence (41.4\% vs. $23.7 \%$ ), $\chi^{2}(1)=4.425, p<.035$, and more likely than bystanders to refrain from reporting due to believing the police could not do anything (27.6\% vs. $12.1 \%), \chi^{2}(1)=5.545, p<.019$. Further, when added to the discriminant function analyses described below, target status was not a significant predictor of response type. Because of these infrequent and isolated differences, the remaining analyses do not consider results for these two groups separately.

\section{Differential Reasons for Not Reporting}

Discriminant analysis was used to determine if nonresponders and informal responders differed according to gender, type of threatening behavior observed, and reasons for failing to report the threatening behavior. Table 2 presents a summary of the univariate and bivariate analyses. Response behaviors did not differ according to the gender of the participant or the type of threatening behavior being observed. However, individuals who took no action and those who informally intervened endorsed different reasons for failing to report the threatening behavior.

Table 2. Significant Differences in Reasons Among Response Groups

\begin{tabular}{|c|c|c|c|c|}
\hline & $\begin{array}{l}\text { No action } \\
n=178 \\
M(S D)\end{array}$ & $\begin{array}{l}\text { Informal response } \\
n=184 \\
M(S D)\end{array}$ & $\begin{array}{l}\text { Report } \\
n=51 \\
M(S D)\end{array}$ & $F(p$ value $)$ \\
\hline \multicolumn{5}{|l|}{ Reasons for not reporting } \\
\hline A dangerous situation did not appear likely & $72(40.4)$ & $40(21.7)$ & & $12.851(<.001)$ \\
\hline A dangerous situation did not appear immediate & $70(39.3)$ & $50(27.2)$ & & $4.707(.030)$ \\
\hline I did not want to get involved & $70(39.3)$ & $31(16.8)$ & & $22.157(<.001)$ \\
\hline It seemed like a personal matter, not a police matter & $49(27.5)$ & $85(46.2)$ & & $14.160(<.001)$ \\
\hline I thought it might make the situation worse & $23(12.9)$ & $45(24.5)$ & & $8.184(.004)$ \\
\hline $\begin{array}{l}\text { The individual typically acts threatening without } \\
\text { committing violence }\end{array}$ & $17(9.6)$ & $39(21.2)$ & & $9.665(.002)$ \\
\hline $\begin{array}{l}\text { My relationship with the potentially dangerous } \\
\text { individual }\end{array}$ & $7(3.9)$ & $23(12.5)$ & & $9.522(.002)$ \\
\hline \multicolumn{5}{|l|}{ Reasons for taking action } \\
\hline A dangerous situation appeared immediate & & $22(12.0)$ & $20(39.2)$ & $19.462(<.001)$ \\
\hline My awareness of available campus resources & & $11(6.0)$ & $18(35.3)$ & $30.811(<.001)$ \\
\hline $\begin{array}{l}\text { The potentially dangerous individual had made serious } \\
\text { and/or specific threats }\end{array}$ & & $13(7.1)$ & $13(25.5)$ & $13.251(<.001)$ \\
\hline
\end{tabular}




\begin{tabular}{|c|c|c|}
\hline $\begin{array}{l}\text { Nonresponders } \\
\qquad \begin{array}{c}n=178 \\
-.494\end{array}\end{array}$ & & $\begin{array}{c}\text { Informal Responders } \\
\mathrm{n}=184 \\
.500\end{array}$ \\
\hline+ & + & $\Lambda$ \\
\hline-1.00 & 0 & 1.00 \\
\hline Significant Reasons (Structure Weight): & & Significant Reasons (Structure Weight): \\
\hline I did not want to get involved (-.489) & & Personal matter, not a police matter (.385) \\
\hline $\begin{array}{l}\text { Dangerous situation did not appear } \\
\text { likely }(-.393)\end{array}$ & & $\begin{array}{l}\text { Individual typically acts threatening without } \\
\text { committing violence }(.346)\end{array}$ \\
\hline $\begin{array}{l}\text { Dangerous situation did not appear } \\
\text { immediate }(-.261)\end{array}$ & & $\begin{array}{l}\text { My relationship with the individual }(.302) \\
\text { I might make the situation worse }(.288)\end{array}$ \\
\hline
\end{tabular}

Figure 1. Discriminating reasons between nonresponders and informal responders for failing to report concerning behaviors.

Multivariate analysis significantly distinguished between nonresponders and informal responders, $\lambda=.801, \chi^{2}(19)=75.159, p<.001$, $R^{2}=.446$. The model was able to correctly reclassify $66.0 \%$ of participants. Specifically, $65.3 \%$ of nonresponders were correctly identified, and $66.7 \%$ of informal responders were reclassified. Figure 1 gives a graphical depiction of the multivariate results. Our hypotheses were partially supported for why students failed to report concerning behavior. Consistent with our predictions, level of involvement could be distinguished based upon perceptions of immediate and likely dangerousness. Nonresponders were more likely to perceive a dangerous situation as being neither likely nor immediate. However, trust in police, perceived significance of the situations, and awareness of campus resources were not differentially endorsed as reasons. Similarly, feelings of campus connectedness did not differ between the two groups. Participants who took no action were less likely to want to get involved than those who took some form of informal action. Additionally, informal responders were more likely to see the situation as a personal matter, fear making the situation worse, and know the potentially dangerous individual to habitually make threats without acting violence.

\section{Differential Reasons for Taking Some Action}

Discriminant analysis was used to determine if nonresponders and informal responders differed according to gender, type of threatening 


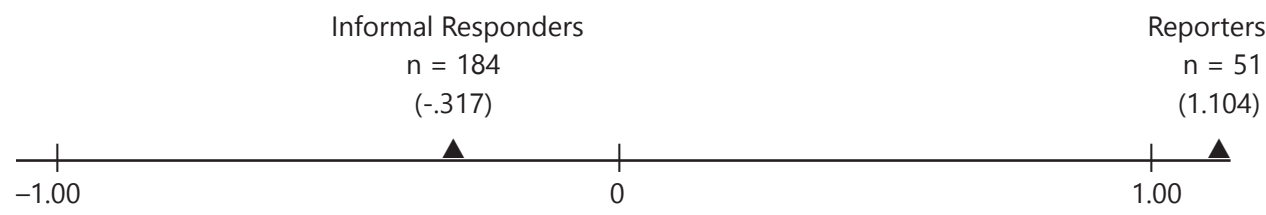

Significant Reasons (Structure Weight):

Aware of campus resources (.666)

Danger seemed immediate (.513)

The individual made serious/specific threats (.439)

A dangerous situation was likely (.224)

Behavior was harming myself or someone else (.215)

Figure 2. Discriminating reasons between informal responders and reporters for taking some form of action in response to concerning behaviors.

behavior observed, and reasons for taking some form of action. Table 2 presents a summary of the univariate and bivariate analyses. Contrary to our hypothesis, gender was unrelated to reporting decision. Although the type of threatening behavior was not significant, increased severity and specificity of threats did distinguish between groups. Multivariate analysis was able to significantly reclassify $79.5 \%$ of informal responders and reporters, $\lambda=.739, \chi^{2}(13)=65.237, p<$ $.001, R^{2}=.511$. Specifically, $83.9 \%$ of informal responders were correctly identified, and $64.0 \%$ of reporters were reclassified. Our hypotheses were partially supported for why students exerted different degrees of involvement in response to concerning behaviors. Those who reported the behavior to authorities were more likely to see the situation as dangerous and imminent. As previously mentioned, while reporters were not more likely to have observed a direct threat, they were more likely to have observed a specific and/or serious threat. Interestingly, reporters were more aware of campus resources compared with informal responders. Figure 2 gives a graphical depiction of the multivariate results.

\section{Discussion}

Targeted violence tends to be preceded by observable behaviors (Calhoun \& Weston, 2003). Research on college campuses indicates that the reporting of these preincident behaviors can be effective in 
preventing or disrupting future violent acts (e.g., Daniels et al., 2007). Unfortunately, low reporting rates for these behaviors have been demonstrated throughout the literature (Catalano, 2012; Nekvasil \& Cornell, 2012; Rand \& Robinson, 2011). Although preincident reporting has been recognized as critical to the prevention of targeted violence on campuses, most research on this issue has been limited to vignette designs (Hollister \& Scalora, 2015). In the current study, 30.4\% of a general collegiate sample observed actual preincident behaviors. This is relevant in light of findings that clearly demonstrate the harm posed by serious preincident behaviors, even those without features of violence (e.g., stalking, verbal threats). For example, victims of stalking experience multiple psychiatric symptoms (e.g., social dysfunction, suicidality) irrespective of the presence of physical assault (Blaauw, Winkel, Arensman, Sheridan, \& Freeve, 2002).

Only $12.3 \%$ of those who were aware of the behaviors formally reported this information to campus authorities. The reasons provided by participants suggest reporting rates might have been higher had more severe behaviors been observed. Of the 413 students who reported an awareness of preincident behaviors, 39 (i.e., 9.4\% of the original sample) reported physical assault, $46(11.1 \%)$ reported sexual assault, and $6(1.5 \%)$ reported both physical and sexual assault from the same individual. Of note, age, gender, ethnicity, and education were not significant predictors of response behaviors. Rather, decisions were based upon attitudes and perceptions of the circumstances. Several factors distinguished students taking no action, informal action, or reporting to authorities, and these factors can be used by campus safety professionals to improve reporting across concerning behaviors.

The likelihood, immediacy, and potential harm of a dangerous situation were the main motivations noted by reporters of preincident behavior, which is consistent with the heightened reporting for severe offending behavior (Goudriaan, Wittebrood, \& Nieuwbeerta, 2006). Reporting students viewed their interpretations of dangerousness as indicative of future violence, and therefore as relevant and worth reporting. This finding corresponds with past studies suggesting that the perception of clear and present danger is critical to the reporting of concerning incidents to authorities (Buhi et al., 2009; Calhoun \& Weston, 2003; Hollister \& Scalora, 2015; Paull et al., 2012; Thompson et al., 2007). Unfortunately, students have been shown to misjudge the likelihood and immediacy of future violence (Pollack et al., 2008). As 
such, overreliance by authorities on student interpretations of dangerousness may impede effective threat assessment processes across campus safety concerns. Reporting students also noted the seriousness and specificity of threats from the perpetrator impacted their decision, which replicates vignette findings in college student samples (Hollister et al., 2015; Tarling \& Morris, 2010). However, many campus attacks have occurred without direct threats (Drysdale et al., 2010), and a range of additional preincident behaviors have been considered necessary in distinguishing between those making threats and those who pose a threat (Calhoun \& Weston, 2009).

Similar to findings in the bullying and sexual assault prevention literature (Frey, Hirschstein, Edstrom, \& Snell, 2009; Polanin, Espelage, \& Pigott, 2012), awareness of how to report was related to formally reporting preincident behavior. Over one third of formal reporters expressed that awareness of campus resources impacted their decision, which suggests understanding the appropriate avenues of resolution relate to the decision to inform authorities (i.e., consistent with findings from Hollister et al., 2014; Paluck \& Shepherd, 2012; and Pollack et al., 2008).

Students in the current sample who failed to take action in response to concerning behaviors tended not to view the preincident behavior as indicative of future violence, consistent with previous findings (Pollack et al., 2008). These students perceived that a dangerous situation did not appear immediate or likely, which suggests that observers' assumptions of dangerousness and risk factors may hinder campus authorities from implementing effective prevention strategies. Additionally, students who failed to take any action in response to threatening situations indicated they did not want to get involved. These students may have considered the risks of reporting to outweigh the benefits. Consistent with existing literature, this reluctance may entail many components including fear of retaliation, lack of trust in the police, belief that the preincident behavior represents limited risk for actual future violence, partial involvement in the misbehavior, or minimization of the behavior (Goudriaan et al., 2006; Hollister et al., 2014; Tarling \& Morris, 2010; Yamawaki et al., 2012). Students taking no action in response to concerning behavior might also doubt or misunderstand the importance and utility of proactive responses, or be concerned about the potential of harm to themselves if they decide to report a concerning behavior (i.e., retribution). 
The largest proportion of students in the current sample responded informally following exposure to concerning behaviors. Consistent with findings from Pershing (2003), these students often considered their assisting of the individual as a personal matter. Nearly half of the informal responders indicated that the personal nature of the preincident situation prevented them from contacting police, despite their concerns that a dangerous situation appeared likely. These informal responders expressed concerns about making the issue worse through contacting authorities and did not typically consider the problem immediate. In addition, students in this sample who responded informally did not view the preincident behaviors as entailing high enough risk to contact the police, similar to previous findings (Pershing, 2003). These students may have considered the risk sufficient to perform some action, but the likelihood and immediacy of violence was not seen as enough to outweigh loyalties to peers. Thus, students engaging in informal management strategies perceived an ongoing situation that required some protective action, but did not view authority involvement as a plausible or necessary solution.

Last, targets were less likely to formally report preincident behaviors if the behaviors lacked specific threats of violence and the target believed the police were unable to assist with the situation. Targets were also more likely to consider their relationship to the potentially dangerous individual when deciding how to report the behavior. The extent to which the relationship among bystanders, targets, and potentially dangerous individuals affects reporting above and beyond the influence of other factors (e.g., the severity of the incident) or additional reasons for making response decisions is unclear. This is a potentially important area for continued research in order to ascertain the degree to which intervention strategies should account for relationships as obstacles to reporting decisions.

\section{Potential Applications of Findings}

As noted earlier, the majority of the sample endorsed informal responses to concerning situations. While it might be encouraging that these individuals are taking some form of action, this type of response may increase risk for the bystander or victim. As such, help-seeking interventions may be useful for providing practical assistance and 
ensuring safety in addition to hard-handed approaches. Barriers to help seeking, and strategies for overcoming these obstacles, have been extensively examined in the domestic violence literature and may offer guidance for improving such efforts in the domain of targeted violence. For instance, Fugate and colleagues (2005) identified similar barriers to domestic violence help seeking as found in this study for reporting (e.g., perceiving the situation as not too serious, relationship with the dangerous individual). They recommended public awareness campaigns and policy reforms to ensure that agencies focus on victim safety and confidentiality in addition to criminal justice interventions, such as mandatory arrest.

The current findings indicate that perceptions of police incentive and efficacy are important targets for campus interventions. Campus campaigning that presents the campus authorities as individuals who can provide referrals or less formal interventions for struggling individuals, such as in community policing, may increase the utilization of campus police in cases of concerning behaviors (Bartling, Yardley, \& Evans, 2010). Challenging perceptions that police are indifferent toward less severe preincident behaviors, or too busy to manage situations that are not immediate or acute, may soften negative stereotypes about law enforcement and invite more trust in police forces.

Additionally, in this sample, disinterest in getting involved and not viewing concerning behaviors as indicative of future violence were two highly cited reasons for failing to take action. These two attitudes could be targeted by interventions to increase reporting on campus. Interventions could address these factors using a number of methods, such as peer-education interventions with small groups of students who are unlikely to report, as in Hollister et al. (2014), or through other intervention methods that allow for multiple learning experiences and demonstration of prosocial norms (Foubert \& Perry, 2007; Paul \& Gray, 2011). To avoid generating defensive attitudes, intervention methods could incorporate examples that fit well with students' preexisting self-concepts while presenting material that portrays the violence risk inherent in preincident behaviors. For example, a small-group intervention for a fraternity group could portray a stalking situation with several observations of warning behaviors preceding an assault; the participants would draw parallels to relationship problems on campus (similar to the intervention described in Foubert \& Perry, 2007). 
Thus, small group interventions that aim to increase risk awareness could enhance student willingness to assist with campus safety efforts.

Campus reporting interventions could also seek to incentivize students who may informally respond to share their information to authorities. Because informal responders in this sample were dissuaded from reporting due to the personal nature of the behaviors and perceptions of low-level danger, interventions could emphasize the range of preincident behaviors related to subsequent violence and campus police could facilitate assistance for struggling students. Interventions such as these could be incorporated into already existing sexual assault prevention efforts, freshman orientation (for interventions targeting younger students), and judicial affairs efforts (for interventions targeting delinquent students). Further, creating an avenue for observers of concerning behavior to anonymously consult with law enforcement without revealing the identity of the struggling individual could especially benefit informal responders, who are aware of the situation and have some motivation to intervene, but are not yet convinced that the risk of the situation outweighs the benefits of remaining silent.

Despite the recognized need for campus preincident reporting, there is a dearth of evidence on the development, implementation, and effectiveness of interventions aimed at improving reporting rates among collegiate stakeholders (Hollister \& Scalora, 2015). The findings of this study suggest multiple target areas that may act as the basis for such interventions. Additionally, secondary analysis of national criminological reports (e.g., victimization surveys), violence prevention efforts (e.g., antibullying campaigns), and incident characteristics (e.g., more severe crimes are more likely to be reported) may provide insight to the features of emphasis in preincident reporting interventions on college campuses (Hollister \& Scalora, 2015; Hollister, Scalora, Hoff, Hodges, \& Marquez, 2016). Interventions may also be guided by previous college policing efforts aimed at other areas of concern to campus safety, such as sexual assault or alcoholism. The challenge moving forward is to continue exploring reasons for response behaviors to preincident observations and utilize information on reporting decisions to devise, test, and modify the application of preincident reporting enhancement programs. 


\section{Limitations}

Some limitations of the current study should be noted. First, self-report methods were used to measure response decisions and influencing factors. As a result, the data may not represent accurate observation reports or the influences on reporting behavior. Indeed, research comparing survey responses to actual behaviors, such as Internet gambling, indicate that self-report based research may be less accurate than behavioral observations for a variety of reasons (e.g., recall difficulties, participant bias, different understandings of target behaviors; Shaffer, Peller, LaPlante, Nelson, \& LaBrie, 2010), and commentators have advocated for a paradigm shift in social science research to utilize more direct observation techniques (Baumeister, Vohs, \& Funder, 2007). Second, the response options included in the questionnaires regarding influences on reporting behaviors were not exhaustive, so the analyses may have missed some influencing factors. Third, response options were not exclusive or ordinal. Therefore, the relative importance of any one reason among multiple influences could not be examined, and we were unable to analyze the potential development of reasoning over time.

\section{Conclusion}

In spite of these limitations, the current study informed the important and understudied area of student responses to concerning behavior and threats to campus safety. A greater understanding of why some behaviors are reported to campus authorities, while others are reported less formally (or not at all) has important implications for effective campus violence prevention. The current findings suggest a number of campus reporting intervention strategies that can enhance the ability of campus police, public safety departments, and threat assessment teams (when available) to effectively assess and intervene in situations with concerning behavior. 


\section{References}

Bartling, K., Yardley, O., \& Evans, C. (2010). UNL threat assessment partnership: Communications campaign. Paper presented at the Great Plains Association of Threat Assessment Professionals Meeting. Lincoln, NE.

Baumeister, R. F., Vohs, K. D., \& Funder, D. C. (2007). Psychology as the science of self-reports and finger movements: Whatever happened to actual behavior? Perspectives on Psychological Science, 2, 396 - 403. doi 10.1111/j.1745-6916.2007.00051.x

Blaauw, E., Winkel, F. W., Arensman, E., Sheridan, L., \& Freeve, A. (2002). The toll of stalking: The relationship between features of stalking and psychopathology of victims. Journal of Interpersonal Violence, 17, 50 - 63. doi 10.1177/0886260502017001004

Bosick, S. J., Rennison, C. M., Gover, A. R., \& Dodge, M. (2012). Reporting violence to the police: Predictors through the life course. Journal of Criminal Justice, 40 , 441-451. doi 10.1016/j.jcrimjus.2012.05.001

Brank, E. M., Woolard, J. L., Brown, V. E., Fondacaro, M., Luescher, J. L., Chinn, R. G., \& Miller, S. A. (2007). Will they tell? Weapons reporting by middle-school youth. Youth Violence and Juvenile Justice, 5, 125-146. doi 10.1177/1541204006296171

Buhi, E. R., Clayton, H., \& Surrency, H. H. (2009). Stalking victimization among college women and subsequent help-seeking behaviors. Journal of the American College Health Association, 57, 419-426. doi 10.3200/JACH.57.4.419-426

Calhoun, F. S., \& Weston, S. W. (2003). Contemporary threat management: A guide for identifying, assessing, and managing individuals of violent intent. San Diego, CA: Specialized Training Services.

Calhoun, F. S., \& Weston, S. W. (2009). Threat assessment and management strategies: Identifying the howlers and hunters. Boca Raton, FL: CRC Press.

Catalano, S. (2012). Stalking victims in the United States-Revised (NCJ Publication No. 224527). Washington, DC: Bureau of Justice Statistics.

Cornell, D. G., Sheras, P. L., Kaplan, S., McConville, D., Douglass, J., Elkon, A., ... Cole, J. (2004). Guidelines for student threat assessment: Field-test findings. School Psychology Review, 33, 527-546.

Daniels, J. A., Buck, I., Croxall, S., Gruber, J., Kime, P., \& Govert, H. (2007). A content analysis of new reports of averted school rampages. Journal of School Violence, 6, 83-99. doi 10.1300/J202vo6no1_o6

Drysdale, D., Modzeleski, W., \& Simons, A. (2010). Campus attacks: Targeted violence affecting institutions of higher education. U.S. Secret Service, U.S. Department of Homeland Security, Office of Safe and Drug-Free Schools, U.S. Department of Education, and Federal Bureau of Investigation, U.S. Department of Justice. Washington, DC, 2010.

Fein, R. A., \& Vossekuil, B. (1999). Assassination in the United States: An operational study of recent assassins, attackers, and near-lethal approachers. Journal of Forensic Sciences, 44, 321-333. doi 10.1520/JFS14457J 
Fisher, B. S., Daigle, L. E., Cullen, F. T., \& Turner, M. G. (2003). Reporting sexual victimization to the police and others: Results from a nationallevel study of college women. Criminal Justice and Behavior, 30, 6-38. doi 10.1177/0093854802239161

Foubert, J. D., \& Perry, B. C. (2007). Creating lasting attitude and behavior change in fraternity members and male student athletes: The qualitative impact of an empathy-based rape prevention program. Violence Against Women, 13, 70-86. doi 10.1177/1077801206295125

Frazier, P. A., \& Burnett, J. W. (1994). Immediate coping strategies among rape victims. Journal of Counseling \& Development, 72, 633-639. doi 10.1002/j.15566676.1994.tbo1694.x

Frey, K. S., Hirschstein, M. K., Edstrom, L. V., \& Snell, J. L. (2009). Observed reductions in school bullying, nonbullying aggression, and destructive bystander behavior: A longitudinal evaluation. Journal of Educational Psychology, 101, 466- 481. doi 10.1037/aoo13839

Fugate, M., Landis, L., Riordan, K., Naureckas, S., \& Engel, B. (2005). Barriers to domestic violence help seeking: Implications for intervention. Violence Against Women, 11, 290-310. doi 10.1177/1077801204271959

Goudriaan, H., Wittebrood, K., \& Nieuwbeerta, P. (2006). Neighbourhood characteristics and reporting crime: Effects of social cohesion, confidence in police effectiveness, and socio-economic disadvantage. British Journal of Criminology, 46, 719-742. doi 10.1093/bjc/aziog6

Hollister, B. A., Scalora, M. J., Hoff, S. M., Hodges, H. J., \& Marquez, A. (2016). College student reporting responses to hypothetical and actual safety concerns. Journal of School Violence. Advance online publication. doi 10.1080/15388220.2015.1129498

Hollister, B. A., \& Scalora, M. J. (2015). Broadening campus threat assessment beyond mass shootings. Aggression and Violent Behavior, 25, 43-53. doi 10.1016/j. avb.2015.07.005

Hollister, B., Scalora, M., Hoff, S., \& Marquez, A. (2014). Exposure to preincident behavior and reporting in college students. Journal of Threat Assessment and Management, 1, 129-143. doi 10.1037/tamooooo15

MacDonald, Z. (2001). Revisiting the dark figure a microeconometric analysis of the under-reporting of property crime and its implications. The British Journal of Criminology, 41, 127-149. doi 10.1093/bjc/41.1.127

Meloy, J. R. (2011). Approaching and attacking public figures: A contemporary analysis of communications and behavior. In C. Chauvin (Ed.), Threatening communications and behavior: Perspectives on the pursuit of public figures (pp. 75-102). Washington, DC: The National Academies Press.

Nekvasil, E. K., \& Cornell, D. G. (2012). Student reports of peer threats of violence: Prevalence and outcomes. Journal of School Violence, 11, 357- 375. doi 10.1080/15388220.2012.706764

Paluck, E. L., \& Shepherd, H. (2012). The salience of social referents: A field experiment on collective norms and harassment behavior in a school social 
network. Journal of Personality and Social Psychology, 103, 899-915. doi 10.1037/aoo30015

Paul, L. A., \& Gray, M. J. (2011). Sexual assault programming on college campuses: Using social psychological belief and behavior change principles to improve outcomes. Trauma, Violence, \& Abuse, 12, 99 -109. doi 10.1177/1524838010390710

Paull, M., Omari, M., \& Standen, P. (2012). When is a bystander not a bystander? A typology of the roles of bystanders in workplace bullying. Asia Pacific Journal of Human Resources, 50, 351- 366. doi 10.1111/j.1744-7941.2012.00027.x

Pershing, J. L. (2003). To snitch or not to snitch? Applying the concept of neutralization techniques to the enforcement of occupational misconduct. Sociological Perspectives, 46, 149-178. doi 10.1525/sop.2003.46.2.149

Polanin, J. R., Espelage, D. L., \& Pigott, T. D. (2012). A meta-analysis of schoolbased bulling prevention programs' effects on bystander intervention behavior. School Psychology Review, 41, 47-65.

Pollack, W. S., Modzeleski, W., \& Rooney, G. (2008). Prior knowledge of potential school-based violence: Information students learn may prevent a targeted attack. Washington, DC: U. S. Secret Service \& U.S. Department of Education.

Rand, M. R., \& Robinson, J. E. (2011). Criminal victimization in the United States, 2008. http://www.bjs.gov/index.cfm?ty pbdetail\&iid 2218

Scalora, M. J., Baumgartner, J. V., Hatch Maillette, M. A., Covell, C. N., Palarea, R. E., Krebs, J. A., . . Callaway, D. (2003). Risk factors for approach behavior toward the U.S. Congress. Journal of Threat Assessment, 2, 35-55. doi 10.1300/ J177v02no2_03

Scalora, M., Simons, A., \& VanSlyke, S. (2010). Campus safety: Assessing and managing threats. FBI Law Enforcement Bulletin, 79, 1-10.

Shaffer, H. J., Peller, A. J., LaPlante, D. A., Nelson, S. E., \& LaBrie, R. A. (2010). Toward a paradigm shift in Internet gambling research: From opinion and self-report to actual behavior. Addiction Research \& Theory, 18, 270-283. doi 10.3109/16066350902777974

Skogan, W. G. (1994). Contacts between police and public: Findings from the 1992 British Crime Survey. Norwich, UK: Her Majesty's Stationery Office.

Slocum, L. A., Taylor, T. J., Brick, B. T., \& Esbensen, F. A. (2010). Neighborhood structural characteristics, individual-level attitudes, and youths' crime reporting intentions. Criminology: An Interdisciplinary Journal, 48, 1063-110o. doi 10.1111/j.1745-9125.2010.00212.x

Sulkowski, M. L. (2011). An investigation of student's willingness to report threats of violence in campus communities. Psychology of Violence, 1, 53-65. doi 10.1037/aoo21592

Summers, J. J., Gorin, J. S., Beretvas, S. N., \& Svinicki, M. D. (2005). Evaluating collaborative learning and community. Journal of Experimental Education, 73, 165-188. doi 10.3200/JEXE.73.3.165-188

Tarling, R., \& Morris, K. (2010). Reporting crime to the police. British Journal of Criminology, 50, 474-490. doi 10.1093/bjc/azq011 
Thompson, M., Sitterle, D., Clay, G., \& Kingree, J. (2007). Reasons for not reporting victimizations to the police: Do they vary for physical and sexual incidents? Journal of American College Health, 55, 277-282. doi 10.3200/ JACH.55.5.277-282

Truman, J. L., \& Langton, L. (2014). Criminal victimization, 2013-revised (NCJ Publication No. 247648). Washington, DC: Bureau of Justice Statistics.

Vossekuil, B., Fein, R. A., Reddy, M., Borum, R., \& Modzeleski, W. (2002). The final report and findings of the safe school initiative: Implications for the prevention of school attacks in the United States. Washington, DC: U. S. Secret Service and U.S. Department of Education.

Yamawaki, N., Ochoa-Shipp, M., Pulsipher, C., Harlos, A., \& Swindler, S. (2012). Perceptions of domestic violence: The effects of domestic violence myths, victim's relationship with her abuser, and the decision to return to her abuser. Journal of Interpersonal Violence, 27, 3195-3212. doi 10.1177/o886260512441253 